\title{
Major dietary patterns in relation to menstrual pain: a nested case control study
}

\author{
Nastaran Najafi ${ }^{1}$, Hamidreza Khalkhali ${ }^{2}$, Fatemeh Moghaddam Tabrizi ${ }^{3}$ and Rasoul Zarrin ${ }^{1 *}$ (D)
}

\begin{abstract}
Background: Dysmenorrhea is one of the most prevalent gynecological disorders, experienced by approximately two third of young women during menstruation. According to literature, nutrition can play a key role in the prevalence and severity of dysmenorrhea. This study aims to investigate the relation between dietary patterns and the risk of dysmenorrhea among university students.

Methods: A nested case control study was conducted among 293 students of Urmia University of Medical Sciences who were randomly recruited via a proportional cluster sampling method. From 293 students, 46 students with moderate to severe dysmenorrhea and 54 students without dysmenorrhea were assigned to the case and control groups, respectively. The major dietary patterns of students were identified by factor analysis and the association between dietary patterns and risk of dysmenorrhea was investigated using logistic regression analysis in SPSS 20.

Results: Three major dietary patterns were found and nominated as "Lacto-vegetarian", "Snacks" and "Mixed food items" patterns. After controlling for family history of dysmenorrhea, subjects in the second and third tertiles of "snacks" pattern had a $4.23(95 \% \mathrm{Cl}=1.32-13.58, P=0.01)$ and $3.41(95 \% \mathrm{Cl}=1.10-10.50, P=0.03)$ times, respectively, higher chance to experience moderate to severe dysmenorrhea in comparison with subjects in the first tertile. There was no significant association between the risk of dysmenorrhea and two other dietary patterns.
\end{abstract}

Conclusions: The results indicate that adherence to "snacks" pattern is associated with an increased risk of moderate to severe dysmenorrhea during menstruation among young women.

Keywords: Dysmenorrhea, Dietary pattern, Factor analysis

\section{Background}

Dysmenorrhea is one of the most common gynecologic complaints reported by young women [1]. Dysmenorrhea refers to painful cramps occurring in the lower abdomen or pelvis during menstruation [2] and is experienced by $60-70 \%$ of young women $[3,4]$. Although dysmenorrhea is not considered a life-threatening disorder, it may reduce quality of life and satisfaction as it can interfere with daily activities as well as familial or social relationships [5]. One of the well-known mechanisms for dysmenorrhea is the elevated release of prostaglandins into the uterine tissue once the menstruation begins. These metabolites increase vasoconstriction and myometrial contractions causing uterine ischemia and pain [1]. In order to relieve menstrual pain, non-steroidal anti-inflammatory drugs

\footnotetext{
* Correspondence: rasoul.zarrin@uqconnect.edu.au

${ }^{1}$ Department of Nutrition, School of Medicine, Urmia University of Medical

Sciences, Urmia, Iran

Full list of author information is available at the end of the article
}

(NSAIDs) and oral contraceptive pills (OCPs) are the most preferred medicines used by women [1]. Some potential risk factors of dysmenorrhea are young age (less than 30 years old), body mass index (BMI) less than 20, early menarche, aberrant menstrual flow, longer menstrual cycles, family history of dysmenorrhea and stress [6]. Although the evidence on the relationship between dietary factors and dysmenorrhea is inconclusive, it seems that high consumption of fish, fruits and fiber may reduce the intensity of menstrual pain [7].

To our knowledge, limited studies have investigated the association between dietary patterns and dysmenorrhea. Recently, focusing on dietary pattern approaches has been considered an alternative method to evaluate the association between diet and risk of diseases [8]. Unlike a single-food approach, dietary patterns declare the habitual consumption of individuals according to proportion, frequency and variation of food, drinks and

(c) The Author(s). 2018 Open Access This article is distributed under the terms of the Creative Commons Attribution 4.0 International License (http://creativecommons.org/licenses/by/4.0/), which permits unrestricted use, distribution, and 
nutrients [9]. Although single-food analyses deliver valuable results, they encounter conceptual and methodological limitations. Since people consume food in the form of meals instead of isolated dietary items, the effect of nutrients and food can synergise or interact with each other, which can hinder the examination of their separate effects [8]. Furthermore, single-food analysis could be confounded by the effect of dietary patterns [8]. In a crossover clinical trial conducted by Barnard et al. [10], an intervention with a low fat vegetarian diet for two menstrual cycles diminished duration and severity of dysmenorrhea. This study aims to examine the relationship between dietary patterns and risk of dysmenorrhea among single and healthy female students of Urmia University of Medical Sciences.

\section{Methods}

\section{Design and participants}

A nested case control study was conducted from April to July 2016 in a medical college located in Urmia, in the West Azarbaijan province of Iran. This University comprises 7 faculties (Medicine, Pharmacy, Paramedical, Health, Nursing and Midwifery, Dentistry and International Branch) and administers 5 teaching hospitals. The sample size was calculated by the following formula:

$$
\mathrm{n}=\frac{\frac{\mathrm{z}^{2} \mathrm{pq}}{\mathrm{d}^{2}}}{1+\frac{1}{\mathrm{~N}}\left(\frac{\mathrm{z}^{2} \mathrm{pq}}{\mathrm{d}^{2}}-1\right)}
$$

( $\mathrm{n}=$ the minimum sample size, $\mathrm{N}=$ population size (1972), $\mathrm{z}=1.96$ for $95 \%$ confidence level, $\mathrm{p}$ (the prevalence of dysmenorrhea $[11])=0.74, q=0.26$ and $d$ (the degree of precision $)=0.05$ ). However, taking into account the possible sample loss, a total of 386 samples were estimated. Students were selected by a cluster sampling method. The research team distributed self-administered questionnaires among participants. Students with energy intakes outside the range of 500-5000 kcal/day [12] and those who did not answer more than 20\% of Food Frequency Questionnaire (FFQ) items were excluded from the study $(n=93)$ and dietary patterns of 293 students were extracted. Out of 293 students, 60 subjects without dysmenorrhea and 60 subjects with 2nd to 3rd grade dysmenorrhea were randomly assigned to each of control and case groups, respectively. The inclusion criteria in this section was the presence of menstrual periods, being single, not having any chronic diseases, no history of abdominal surgery, no history of alcohol intake and cigarette smoking, no administration of OCPs, dietary supplements and herbal remedies. Body weight and height of both case and control groups were measured and a gynecologist performed abdominal examination and trans-abdominal ultrasonography using an ultrasound scanner (SIUI, CTS-5500, Guangdong, China) to rule out subjects with genital diseases associated with dysmenorrhea (e.g., congenital malformation of the mullerian system, cervical stenosis and ovarian cysts [1]) $(n=20)$. Flow chart of sampling procedure for the study is shown in Fig. 1.

\section{Data collection}

The study questionnaire included five sections. In the first section, students were asked to state their demographic information. In the second section, they were asked about their menstrual characteristics over the last 6 months, including severity of dysmenorrhea, age at menarche, bleeding length, length and regularity of

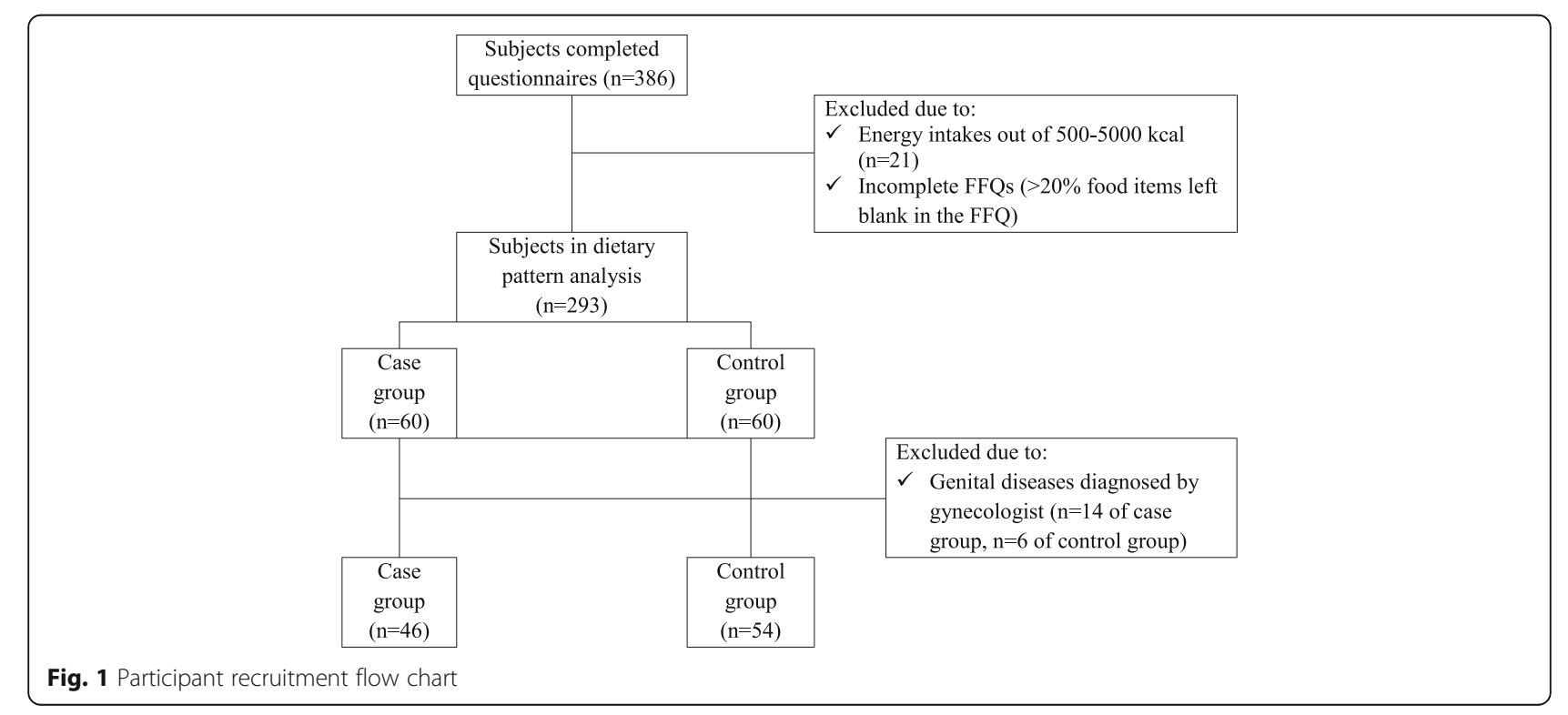


menstrual cycle, severity of menstrual flow and family history of dysmenorrhea. A verbal multidimensional scoring system [13] was used to assess the severity of dysmenorrhea. Based on the pain intensity and its effect on daily activity, symptoms, and the need for analgesics, dysmenorrhea was categorized into four grades: zero (none), 1 (mild), 2 (moderate) or 3 (severe). For the other menstrual characteristics, the questions of the Women's Health Symptom Survey [14] were used. In the third section, physical activity level was assessed by the short form of International Physical Activity Questionnaire $[15,16]$. In this instrument, students were asked to report the frequency and duration of their last 7 days vigorous and moderate activities, walking and sitting. According to the scores, students were categorized into three levels of physical activity: "low" if participants had low activities or did not meet moderate or high category criteria, "moderate" if they had vigorous activities for 3 days or more (at least $20 \mathrm{~min}$ per day), a combination of moderate activities and/or walking for 5 days or more (at least 30 min per day) or a combination of walking, moderate or vigorous activities for at least 5 days with MET (Metabolic Equivalent of Task)-minutes/week $\geq 600$, and "high" if they had vigorous activities for at least 3 days with MET-minutes/week $\geq 1500$ or a combination of walking, moderate or vigorous activities for at least 7 days with MET-minutes/week $\geq 3000$. In the fourth section, participants' depression and anxiety levels over the last 2 weeks were assessed by Patient Health Questionnaire-4 [17]. This instrument had 4 items: the first and second questions measured depression and the third and fourth questions measured anxiety. The response options were "not at all", "several days", "more than half days", and "nearly every day", which were scored as 0, 1, 2 and 3, respectively. Based on their total scores, students were categorised into four groups: normal (0-2), mild (3-5), moderate (6-7) and severe (9-12). In the fifth section, the participants' dietary intakes for the last 6 months were assessed by a 115 -item semi quantitative FFQ. This questionnaire was adapted from Block design [18] and Tehran Lipid and Glucose Study [19]. The frequency of food intakes options were "2-3 times per day", "daily", "4-6 times per week", "2-3 times per week", "weekly", "2-3 times per month", "monthly", "1-5 times during the previous 6 month" and "never". A picture of different portion sizes was given for some food items and for other items, standard household measures (for example "cup" for drinks) or standard units were used. Daily intake of food items (gram/day) was calculated using both frequencies and portion sizes. Total energy intake (kcal/day) of subjects was calculated according to the data available at USDA (United States Department of Agriculture) national nutrient database [20] or other sources [21, 22]. Then, food items were categorized into 30 separate groups based on the previous studies $[23,24]$ or similarities in their nutrient profile. The FFQ was validated with two $24 / \mathrm{h}$ dietary recalls and the correlation coefficients ranged from 0.08 (low fat dairy products) and 0.64 (for high fat dairy products) for food groups.

Body weight was measured (without shoes and in light clothing) to the nearest $0.01 \mathrm{~kg}$ using a digital scale (Beurer BF18 Digital Scale). Height was measured in the standing position without shoes to the nearest $0.1 \mathrm{~cm}$. BMI was calculated by dividing weight in kilogram by their height in meters squared.

\section{Data analysis}

All statistical analyses were performed using IBM SPSS Software Package for Windows (version 20.0, Armonk, NY: IBM Corp). The Kolmogorov-Smirnov test was used to determine whether continuous variables follow a normal distribution. Independent-samples t-test, MannWhitney U test, Pearson chi squared test and Fisher's exact test were used to compare continuous or categorical variables between case and control groups. To identify dietary patterns, principal component analysis was carried out and the factors were rotated by varimax rotation. According to factor eigenvalue greater than 1.8, the break point of the scree plot and factor interpretability, factors (dietary patterns) were noted. These factors were nominated based on food groups with factor loading $>0.2$. After computing factor scores for each individual, we categorized participants by tertiles of scores and the first tertile was considered as a reference. We used logistic regression to calculate the crude and adjusted odds ratios (OR) and the $95 \%$ confidence intervals to interpret the association between dietary patterns and risk of dysmenorrhea. Adjusted ORs were calculated by adjusting for family history of dysmenorrhea. A $P$ value of $<0.05$ was considered statistically significant.

\section{Results}

Among 293 students, the frequency of dysmenorrhea was 74.3\% (95\% CI; 69.3, 79.3\%) (Mild dysmenorrhea was $17.7 \%$, moderate dysmenorrhea was $45.7 \%$ and severe dysmenorrhea was $10.9 \%$ ). The mean \pm SD (Standard Deviation) values for age of participants was $22.2 \pm 2.18$ years (range, 19-30), age at menarche was $13.23 \pm 1.34$ years (range, 9-18), length of menstrual cycle was $28.39 \pm 3.45$ days (range, 20-50) and bleeding length was $5.6 \pm 1.47$ days (range, 2-11). As for marital and residential status, of the 293 students, $266(90.8 \%)$ were single (9.2\% were married) and 165 (54.3\%) resided at the dormitories. The menstrual characteristics, physical activity and depression/anxiety levels of 46 cases and 54 controls are shown in Table 1. Compared to the control group, cases tended to have higher levels of menstrual flow $(F=5.89, P=0.01)$, higher 
Table 1 Characteristics of the case and control groups

\begin{tabular}{|c|c|c|c|}
\hline Variables & Cases $(n=46)$ & Controls $(n=54)$ & $P$-value ${ }^{a}$ \\
\hline Age (y) (Mean \pm SD) & $21.89 \pm 1.43$ & $21.92 \pm 1.83$ & 0.41 \\
\hline Age at menarche $(y)($ Mean \pm SD) & $13.43 \pm 1.47$ & $13.61 \pm 1.43$ & 0.28 \\
\hline Length of menstrual cycle (days) & $28.63 \pm 1.92$ & $28.44 \pm 3.23$ & 0.19 \\
\hline Menstrual cycle regularity, n (\%) & & & 0.49 \\
\hline Yes & $46(46.9)$ & $52(53.1)$ & \\
\hline No & 0 & $2(100)$ & \\
\hline Bleeding length (days) & $5.52 \pm 1.5$ & $5.19 \pm 1.1$ & 0.09 \\
\hline Severity of menstrual flow, n (\%) & & & 0.01 \\
\hline Low & 0 & $3(100)$ & \\
\hline Moderate & $30(41.7)$ & $42(58.3)$ & \\
\hline Severe & $16(64)$ & $9(36)$ & \\
\hline Family history of dysmenorrhea, n (\%) & & & $<0.001$ \\
\hline Yes & $41(56.9)$ & $31(43.1)$ & \\
\hline No & $5(17.9)$ & $23(82.1)$ & \\
\hline Physical activity level, n (\%) & & & 0.71 \\
\hline Low & $11(47.8)$ & $12(52.2)$ & \\
\hline Moderate & $27(48.2)$ & $29(51.8)$ & \\
\hline High & $8(38.1)$ & $13(61.9)$ & \\
\hline Depression-anxiety levels, n (\%) & & & 0.02 \\
\hline Normal & $9(30)$ & $21(70)$ & \\
\hline Mild & $24(49)$ & $25(51)$ & \\
\hline Moderate & $8(80)$ & $2(20)$ & \\
\hline Severe & $5(45.5)$ & $6(54.5)$ & \\
\hline BMI $\left(\mathrm{kg} / \mathrm{m}^{2}\right),($ Mean $\pm \mathrm{SD})$ & $21.71 \pm 2.69$ & $21.59 \pm 2.39$ & 0.4 \\
\hline Daily energy intake (Kcal), (Mean \pm SD) & $2655.20 \pm 822.39$ & $2706.99 \pm 892.50$ & 0.59 \\
\hline
\end{tabular}

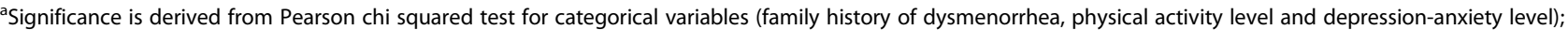
fisher's exact test for severity of menstrual flow and cycle regularity; independent-samples t-test for BMI and daily energy intake and Mann-Whitney $U$ test for age, age at menarche, length of menstrual cycle and bleeding length

frequency of family history of dysmenorrhea (Pearson chi squared $=12.4, \mathrm{df}=1, P<0.001)$ and higher levels of depression and anxiety (Pearson chi squared $=7.92, \mathrm{df}=3$, $P=0.02$ ). No significant difference was found in other characteristics between case and control groups.

Food items in the FFQ were summarized in 30 groups shown in Table 2. Adequacy of sample size and suitability of data for applying factor analysis were confirmed by Kaiser-Meyer-Olkin $(\mathrm{KMO}=0.603)$ and Bartlett's tests $(P<0.001)$. Three major patterns were derived which explained $23.65 \%$ of total variance. Factor loading values of food groups for dietary patterns are shown in Table 3. "Lacto-vegetarian" pattern, explained $10.65 \%$ of total variance, included high intakes of vegetables (all kinds), legumes, fruits, dairy products, vegetable patties (an Iranian egg-based food), nuts, pickles and butter. "Snacks" pattern explained $6.76 \%$ of variance and had high factor loadings on sugars, salty snacks, sweets and desserts, tea and coffee, salt, fruit juices and added fat.
"Mixed food items" pattern explained the least variance (6.23\%) and included high intakes of poultry, mayonnaise, sugar sweetened beverages, fast food, potatoes, egg and red meats.

Crude odds ratios for risk of dysmenorrhea across the tertiles of derived dietary patterns are presented in Table 4. Subjects in the second and third tertiles of the "snacks" pattern, had a 4.07 (95\% CI: $1.35-12.22, P=0.01)$ and 3.15 (95\% CI: $1.09-9.12, P=0.03)$ times, respectively, greater chance to experience 2 nd to 3rd grade dysmenorrhea in comparison with subjects in the first tertile. There was no significant association between dysmenorrhea and the other two patterns. Adjusted odds ratios for dysmenorrhea risk across the tertiles of "snacks" pattern are shown in Table 5. After controlling for family history of dysmenorrhea, the results for "snacks" pattern stayed relatively unchanged and subjects in the second and third tertiles were 4.23 (95\% CI: $1.32-13.58, P=0.01)$ and 3.41 (95\% CI: $1.10-10.50, P=0.03$ ) times, respectively, more 
Table 2 Food groups used in factor analysis

\begin{tabular}{|c|c|}
\hline Food groups & Food items \\
\hline Red meats & $\begin{array}{l}\text { Red meats, ground meats, meatballs, } \\
\text { kabob, heart or liver (organ meats) }\end{array}$ \\
\hline Fish & Fish, canned tuna fish \\
\hline Poultry & Chicken (with or without skin) \\
\hline Eggs & Eggs \\
\hline Low fat dairy products & $\begin{array}{l}\text { Low fat milk, low fat yoghurt, dough } \\
\text { (yoghurt drink) }\end{array}$ \\
\hline High fat dairy products & $\begin{array}{l}\text { Whole milk, chocolate milk, high fat } \\
\text { yoghurt, cream cheese, other cheese, } \\
\text { ice cream, cream }\end{array}$ \\
\hline Tea and coffee & Tea, coffee \\
\hline Fruit & $\begin{array}{l}\text { Apples or pears, strawberries, cherries, } \\
\text { apricots, grapes, peaches or nectarines, } \\
\text { figs, cantaloupe or watermelon, bananas, } \\
\text { mangos, persimmons, pomegranates, } \\
\text { kiwis, oranges or tangerines or lemons, } \\
\text { grapefruit, canned fruits, dates, raisins, } \\
\text { dried fruits }\end{array}$ \\
\hline Fruit juices & Fruit juices, fruit nectars \\
\hline Sugar sweetened beverages & $\begin{array}{l}\text { All kinds of sugar sweetened drinks, } \\
\text { carbonated beverages }\end{array}$ \\
\hline Cruciferous vegetables & Cabbage \\
\hline Green leafy vegetables & Spinach, lettuce \\
\hline Yellow vegetables & Carrots \\
\hline Tomatoes & Tomatoes, tomato sauce \\
\hline Other Vegetables & $\begin{array}{l}\text { Green herbs, cucumber, squash or } \\
\text { eggplant, celery, mushrooms, garlic, } \\
\text { onion, radish, peppers, olives, corn, } \\
\text { green beans }\end{array}$ \\
\hline Vegetable patties & $\begin{array}{l}\text { Green Herbs patty, potato patty, } \\
\text { green bean patty }\end{array}$ \\
\hline Legumes & Chickpeas, lentils, beans, peas, soybeans \\
\hline Nuts & Walnuts, almonds, other nuts, Seeds \\
\hline Sweets and desserts & $\begin{array}{l}\text { Puddings, cakes, cookies, cream cakes } \\
\text { or doughnuts, biscuits or wafers }\end{array}$ \\
\hline Pickles & Cucumber pickle, other pickles \\
\hline Butter & Butter \\
\hline Sugars & $\begin{array}{l}\text { Sugars, chocolates, jelly, honey or } \\
\text { jam, candies }\end{array}$ \\
\hline Salt & Table salt \\
\hline Grains & $\begin{array}{l}\text { Iranian breads (lavash, sangak or } \\
\text { barbari), rice, pasta, barley }\end{array}$ \\
\hline Potatoes & Potatoes \\
\hline French fries & French fries \\
\hline Fast food & $\begin{array}{l}\text { Pizza, burgers, chicken sandwiches, } \\
\text { fried chicken, sausages, lunch meats }\end{array}$ \\
\hline Salty snacks & $\begin{array}{l}\text { Potato Chips, corn puffs, crackers, } \\
\text { popcorn }\end{array}$ \\
\hline Mayonnaise & Mayonnaise \\
\hline Added fats & Added fats \\
\hline
\end{tabular}

Table 3 Factor loadings ${ }^{\mathrm{a}}$ of food groups in derived dietary

\begin{tabular}{|c|c|c|c|}
\hline \multirow[t]{2}{*}{ Food groups } & \multicolumn{3}{|l|}{ Dietary patterns } \\
\hline & Lacto-vegetarian & Snacks & Mixed food items \\
\hline Other Vegetables & 0.641 & & \\
\hline Tomatoes & 0.565 & & \\
\hline Yellow vegetables & 0.534 & & \\
\hline Legumes & 0.523 & & \\
\hline Fruit & 0.502 & & \\
\hline Green leafy vegetables & 0.443 & & \\
\hline Cruciferous vegetables & 0.424 & & \\
\hline Low fat dairy products & 0.403 & & \\
\hline Vegetable patties & 0.393 & & \\
\hline High fat dairy products & 0.364 & & 0.287 \\
\hline Nuts & 0.297 & 0.244 & \\
\hline Pickles & 0.275 & & \\
\hline Butter & 0.246 & & \\
\hline Sugars & & 0.694 & \\
\hline Salty snacks & & 0.654 & \\
\hline Sweets and desserts & 0.217 & 0.539 & \\
\hline Tea and coffee & & 0.469 & \\
\hline Salt & 0.292 & 0.456 & \\
\hline Fruit juices & & 0.338 & 0.226 \\
\hline Added fats & & 0.330 & \\
\hline Poultry & & & 0.637 \\
\hline Mayonnaise & & & 0.598 \\
\hline $\begin{array}{l}\text { Sugar sweetened } \\
\text { beverages }\end{array}$ & & & 0.570 \\
\hline Fast food & & 0.382 & 0.441 \\
\hline Potatoes & & & 0.420 \\
\hline Eggs & & & 0.382 \\
\hline Red meats & & & 0.301 \\
\hline French fries & - & - & - \\
\hline Fish & - & - & - \\
\hline Grains & - & - & - \\
\hline $\begin{array}{l}\text { Percent of variance } \\
\text { explained }\end{array}$ & 10.65 & 6.76 & 6.23 \\
\hline
\end{tabular}

${ }^{\mathrm{a}}$ Factor loadings $<0.2$ are omitted for simplicity

likely to experience high grade dysmenorrhea when compared to subjects in the first tertile.

\section{Discussion}

In the present study, three major dietary patterns including "lacto-vegetarian", "snacks" and "mixed food items" were derived using factor analysis. The three patterns explained $23.65 \%$ of total variance. The "snacks" pattern was associated with risk of dysmenorrhea before and after controlling for family history of dysmenorrhea. 
Table 4 Crude odds ratios for dysmenorrhea risk across tertiles of three major dietary patterns

\begin{tabular}{lllll}
\hline Dietary patterns & $\mathrm{B}(\mathrm{SE})^{\mathrm{a}}$ & $\mathrm{OR}^{\mathrm{b}}$ & $\left(95 \% \mathrm{Cl}^{\mathrm{C}}\right)$ & $P^{\mathrm{d}}$ \\
\hline Lacto-vegetarian & & & & 0.47 \\
T1 & - & 1 & - & - \\
T2 & -0.47 & 0.62 & $(0.25-1.56)$ & 0.31 \\
T3 & -0.58 & 0.55 & $(0.19-1.59)$ & 0.27 \\
Snacks & & & & 0.03 \\
T1 & - & 1 & - & - \\
T2 & 1.40 & 4.07 & $(1.35-12.22)$ & 0.01 \\
T3 & 1.15 & 3.15 & $(1.09-9.12)$ & 0.03 \\
Mixed food items & & & & 0.21 \\
T1 & - & 1 & - & - \\
T2 & -0.17 & 0.84 & $(0.39-2.86)$ & 0.73 \\
T3 & -0.82 & 0.43 & $(0.27-1.90)$ & 0.09 \\
\hline
\end{tabular}

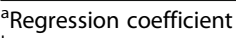

bodds ratio

${ }^{\mathrm{C}}$ Confidence interval

${ }^{\mathrm{d}}$ No potential risk factor was adjusted

According to a provocative commentary by Anderson and Patterson [25], unhealthy snack food (called "junk food") provide suboptimal nutrition and excessive energy, fat, sugar and sodium. Furthermore, over-consumption of these kinds of food, decreases the intakes of nutrientdense food which results in low intakes and low serum concentrations of most micronutrients, e.g., vitamin E, B6 and calcium [26]. A Cochrane review of several clinical trials which summarized the efficacy and safety of dietary interventions for the treatment of dysmenorrhea, have explained the effectiveness of such micronutrients in reducing the duration and intensity of dysmenorrhea [27]. The current study found no association between "lactovegetarian" and risk of dysmenorrhea. This result was inconsistent with the study conducted by Barnard et al. [10] who reported that intervention by a low fat vegetarian diet for two menstrual cycles can reduce the intensity of dysmenorrhea in a sample of 33 women aged at least 18 years old. The diet in the mentioned study included high intakes of cereals, legumes, vegetables and fruits with restriction on animal products, oils, fried food, avocados, olives, nuts,

Table 5 Adjusted odds ratios for dysmenorrhea risk across tertiles of "snacks" pattern

\begin{tabular}{ccccc}
\hline Dietary patterns & $\mathrm{B}(\mathrm{SE})^{\mathrm{a}}$ & $\mathrm{OR}^{\mathrm{b}}$ & $\left(95 \% \mathrm{Cl}^{\mathrm{c}}\right)$ & $P^{\mathrm{d}}$ \\
\hline Snacks & & & & 0.03 \\
$\mathrm{~T} 1$ & - & 1 & - & - \\
$\mathrm{T} 2$ & 1.44 & 4.23 & $(1.32-13.58)$ & 0.01 \\
$\mathrm{~T} 3$ & 1.22 & 3.41 & $(1.10-10.50)$ & 0.03 \\
\hline
\end{tabular}

${ }^{\mathrm{a}}$ Regression coefficient

${ }^{\mathrm{b}}$ Odds ratio

${ }^{c}$ Confidence interval

${ }^{\mathrm{d}}$ Adjusted for family history of dysmenorrhea nut butters and seeds. Since the "lacto-vegetarian" pattern included high-fat dairy products, nuts and butter, it could not be considered a low fat diet. In the mentioned study, both single and married women with a wide range of ages (>18 years) were included to study. Moreover, they did not adjust their analyses for potential cofounders and also did not indicate any exploration of the pathologic diseases of dysmenorrhea through medical examinations. Applying different pain measuring instruments can also explain different findings in both studies. This study has some limitations. First, although ultrasonography was applied to rule out participants with certain underlying genital diseases, this method was not accurate enough to diagnose all of the related diseases. For instance, The gold standard for the diagnosis of endometriosis is laparoscopy [28] which was not applicable in the current study. Hence, discrimination between primary and secondary dysmenorrhea was impossible and menstrual pain as a whole was considered. Second, no additional data about the type of analgesics and their usage pattern during menstruation was obtained from subjects. Third, we evaluated the dietary intakes of individuals using FFQs which increased the possibility of measurement error. Forth, dietary pattern approaches were prone to subjective decisions in the fields of food categorization, selection or nomination of factors which made it difficult to compare the patterns derived by different studies.

\section{Conclusions}

The results of this research imply that diet, characterized by a high consumption of sugars, salty snacks, sweets and desserts, tea and coffee, salt, fruit juices and added fat (labeled as "snacks" pattern), is associated with an increased risk of dysmenorrhea among young women. More research is needed in this field to optimize the dietary patterns of individuals suffering from this problem.

\section{Abbreviations}

BMI: Body Mass Index; Cl: Confidence Interval; FFQ: Food Frequency Questionnaire; KMO: Kaiser-Meyer-Olkin; MET: Metabolic Equivalent of Task; NSAID: Non-Steroidal Anti-Inflammatory Drug; OCP: Oral Contraceptive Pill; OR: Odds Ratio; SD: Standard Deviation; USDA: United States Department of Agriculture

\section{Acknowledgments}

The authors would like to thank all participants who generously gave their time to be part of the study.

\section{Availability of data and materials}

Due to ethical concerns, supporting data cannot be made available.

\section{Authors' contributions}

RZ and HK helped design the study; RZ, NN and FMT designed the study questionnaire; NN and RZ contributed to data collection, interpretation of data and manuscript preparation; HK and NN carried out the statistical analysis; FMT and RZ contributed to the evaluation and the edition of the manuscript; RZ was involved in a critical revision of the manuscript for important intellectual content and supervised the research. All authors have read and approved the final manuscript. 


\section{Ethics approval and consent to participate}

The study protocol was approved by the Ethics Committee of Urmia University of Medical Sciences. The purpose of this research was explained to all students and they were ensured that their responses would remain confidential. Written informed consents were obtained from all participants before inclusion in the study.

\section{Competing interests}

The authors declare that they have no competing interests.

\section{Publisher's Note}

Springer Nature remains neutral with regard to jurisdictional claims in published maps and institutional affiliations.

\section{Author details}

${ }^{1}$ Department of Nutrition, School of Medicine, Urmia University of Medical Sciences, Urmia, Iran. ${ }^{2}$ Department of Biostatistics and Epidemiology, School of Medicine, Urmia University of Medical Sciences, Urmia, Iran. ${ }^{3}$ Department of Midwifery, School of Nursing and Midwifery, Urmia University of Medical Sciences, Urmia, Iran.

Received: 3 July 2017 Accepted: 1 May 2018

Published online: 21 May 2018

\section{References}

1. Harel Z. Dysmenorrhea in adolescents and young adults: an update on pharmacological treatments and management strategies. Expert Opin Pharmacother. 2012;13:2157-70.

2. Katz VL. Comprehensive gynecology. 5th ed. Philadelphia: Mosby Elsevier; 2007

3. Ortiz Ml. Primary dysmenorrhea among Mexican university students: prevalence, impact and treatment. Eur J Obstet Gynecol Reprod Biol. 2010; 152:73-7.

4. Unsal A, Ayranci U, Tozun M, Arslan G, Calik E. Prevalence of dysmenorrhea and its effect on quality of life among a group of female university students. Ups J Med Sci. 2010;115:138-45.

5. lacovides S, Avidon I, Bentley A, Baker FC. Reduced quality of life when experiencing menstrual pain in women with primary dysmenorrhea. Acta Obstet Gynecol Scand. 2014;93:213-7.

6. Ju $\mathrm{H}$, Jones $\mathrm{M}$, Mishra $\mathrm{G}$. The prevalence and risk factors of dysmenorrhea. Epidemiol Rev. 2013;36:104-13.

7. Fjerbaek A, Knudsen UB. Endometriosis, dysmenorrhea and diet-what is the evidence? Eur J Obstet Gynecol Reprod Biol. 2007:132:140-7.

8. Hu FB. Dietary pattern analysis: a new direction in nutritional epidemiology. Curr Opin Lipidol. 2002:13:3-9.

9. Essery Stoody E, Spahn J, McGrane M, MacNeil P, Fungwe T, Altman J, et al. A series of systematic reviews on the relationship between dietary patterns and health outcomes. Alexandria: Evidence Analysis Library Division, Center for Nutrition Policy and Promotion, US Department of Agriculture; 2014.

10. Barnard ND, Scialli AR, Hurlock D, Bertron P. Diet and sex-hormone binding globulin, dysmenorrhea, and premenstrual symptoms. Obstet Gynecol. 2000:95:245-50.

11. Shaebani M, Mohammad Alizadeh S. Primary dysmenorrhea among dormitory students of Tabriz. Tabriz Nurs Midwifery J. 2010;5:15-21.

12. Willett W. Nutritional epidemiology. In: Monographs in epidemiology and biostatistics. 2nd ed. New York: Oxford University Press; 1998

13. Andersch B, Milsom I. An epidemiologic study of young women with dysmenorrhea. Am J Obstet Gynecol. 1982;144:655-60.

14. World Endometriosis Research Foundation-Women's Health Symptom Survey. http://www.endometriosisfoundation.org/WERF-WHSSQuestionnaire-English.pdf.

15. Craig CL, Marshall AL, Sjostrom M, Bauman AE, Booth ML, Ainsworth BE, et al. International physical activity questionnaire: 12-country reliability and validity. Med Sci Sports Exerc. 2003;35:1381-95.

16. IPAQ Research Committee. Guidelines for data processing and analysis of the international physical activity questionnaire (ipaq)-short and long forms. 2005. http://youthrex.com/wp-content/uploads/2017/06/IPAQ-TM.pdf. Accessed 10 Jan 2013

17. Kroenke K, Spitzer RL, Williams JB, Lowe B. An ultra-brief screening scale for anxiety and depression: the PHQ-4. Psychosomatics. 2009;50:613-21.
18. Block G, Hartman AM, Dresser CM, Carroll MD, Gannon J, Gardner L. A databased approach to diet questionnaire design and testing. Am J Epidemiol. 1986;124:453-69.

19. Mirmiran P, Hosseini Esfahani F, Mehrabi Y, Hedayati M, Azizi F. Reliability and relative validity of an FFQ for nutrients in the Tehran lipid and glucose study. Public Health Nutr. 2010;13:654-62.

20. U.S. Department of Agriculture, Agricultural Research Service. USDA national nutrient database for standard reference, release 27. 2014. https://www.ars. usda.gov/northeast-area/beltsville-md-bhnrc/beltsville-human-nutritionresearch-center/nutrient-data-laboratory/docs/sr27-home-page/.

21. Ghazizadeh M, Behnammoradi M. Recipe calculation of six Iranian egg-based dishes (KuKu). Procedia Food Sci. 2015;4:48-54.

22. TürKomp, Turkish Food Composition Database, version 1.0. Food institute, TÜBITAK Marmara Research Center, Gebze/ Kocaeli. 2014. http://www.turkomp.gov.tr. Accessed 11 June 2016.

23. Karimi Z, Jessri M, Houshiar-Rad A, Mirzaei HR, Rashidkhani B. Dietary patterns and breast cancer risk among women. Public Health Nutr. 2014;17: 1098-106.

24. Alizadeh M, Didarloo A, Esmaillzadeh A. Dietary patterns of young females and their association with waist circumference as a health index in northwest of Iran, 2007. Iran Red Crescent Med J. 2015;17:e17594.

25. Anderson JW, Patterson K. Snack foods: comparing nutrition values of excellent choices and "junk foods". J Am Coll Nutr. 2005;24:155-6. discussion 156-7

26. Kant AK. Consumption of energy-dense, nutrient-poor foods by adult Americans: nutritional and health implications. The third national health and nutrition examination survey, 1988-1994. Am J Clin Nutr. 2000;72:929-36.

27. Proctor ML, Murphy PA. Herbal and dietary therapies for primary and secondary dysmenorrhoea. Cochrane Database Syst Rev. 2001;3:Cd002124.

28. Scarselli G, Rizzello F, Cammilli F, Ginocchini L, Coccia ME. Diagnosis and treatment of endometriosis. A review. Minerva Ginecol. 2005:57:55-78.

\section{Ready to submit your research? Choose BMC and benefit from:}

- fast, convenient online submission

- thorough peer review by experienced researchers in your field

- rapid publication on acceptance

- support for research data, including large and complex data types

- gold Open Access which fosters wider collaboration and increased citations

- maximum visibility for your research: over $100 \mathrm{M}$ website views per year

At BMC, research is always in progress.

Learn more biomedcentral.com/submissions 